\title{
Vivências de familiares da pessoa com esquizofrenia
}

\author{
Claudia Maria Sousa de Carvalho ${ }^{1}$ \\ Deisinara Maria Gomes de Sousa ${ }^{2}$ \\ Ranah Isabelle Amorim de Pinho² \\ Márcia Astrês Fernandes ${ }^{3}$ \\ Adélia Dalva da Silva Oliveira ${ }^{4}$
}

\begin{abstract}
Objetivou-se descrever as vivências de familiares da pessoa com esquizofrenia. Estudo descritivo-qualitativo realizado em um Centro de Atenção Psicossocial de Teresina - Piauí. Utilizou-se roteiro de entrevista semiestruturada e procedeu-se a análise de conteúdo à luz do referencial teórico de Bardin. Os resultados revelaram que os familiares sofrem profundos desgastes físicos e emocionais decorrentes do exercício do cuidar da pessoa com esquizofrenia e vivenciam significativos conflitos no convívio diário, comprometendo a qualidade de vida e o funcionamento social e psíquico daqueles que exercem o papel de cuidador. O estudo aponta para a necessidade de elaboração de estratégias de cuidado ao binômio cliente-cuidador.
\end{abstract}

Descritores: Esquizofrenia; Família; Enfermagem.

\footnotetext{
${ }^{1}$ MSc, Professor, Centro Universitário UNINOVAFAPI, Teresina, PI, Brasil. Enfermeira, Fundação Municipal de Saúde de Teresina, Teresina, PI, Brasil.

${ }^{2}$ Aluna do curso de Graduação em Enfermagem, Centro Universitário UNINOVAFAPI, Teresina, PI, Brasil.

${ }^{3} \mathrm{PhD}$, Professor Associado, Departamento de Enfermagem, Universidade Federal do Piauí, Teresina, PI, Brasil. Professor, Centro Universitário UNINOVAFAPI, Teresina, PI, Brasil.

${ }^{4} \mathrm{PhD}$, Professor, Centro Universitário UNINOVAFAPI, Teresina, PI, Brasil. Enfermeira, Fundação Hospitalar de Teresina, Teresina, PI, Brasil.
} 


\section{Experiences of relatives of schizophrenic people}

The purpose of this study was to describe the experiences of family members of the person with schizophrenia. Descriptive-qualitative study conducted at a Psychosocial Care Center in Teresina - Piauí. A semi-structured interview script was used and content analysis was carried out in the light of Bardin's theoretical framework. The results revealed that the family members suffer profound physical and emotional exhaustion resulting from the exercise of the care of the person with schizophrenia and experience significant conflicts in the daily living, compromising the quality of life and the social and psychic functioning of those who exercise the role of caregiver. The study points to the need to develop care strategies for the client-caregiver binomial.

Descriptors: Schizophrenia; Family; Nursing.

\section{Experiencias de los familiares de la persona con esquizofrenial}

Este estudio tuvo como objetivo describir la familia de las experiencias de las personas con esquizofrenia. estudio cualitativo descriptivo en un Centro de Atención Psicosocial de Teresina - Piauí. Se utilizó entrevistas semiestructuradas y se procedió a un análisis de contenidos basado en la marco teórico de Bardin. Los resultados revelaron que los miembros de la familia sufren agotamiento físico y emocional profunda que resulte del ejercicio de la atención de personas con esquizofrenia y la experiencia de los conflictos significativos sobre base diaria, poniendo en peligro la calidad de vida y el funcionamiento social y psicológico de los que ejercen el papel de cuidador. El estudio apunta a la necesidad de elaborar estrategias de atención al binomio cliente-cuidador.

Descriptores: Esquizofrenia; Familia; Enfermería.

\section{Introdução}

Aesquizofrenia representa grave problema de saúde que implica em significativos prejuízos no funcionamento pessoal, social e familiar, caracterizados por retraimento social e limitações para cumprir papeis e corresponder aos relacionamentos. Por isso, o convívio familiar com a pessoa que sofre de esquizofrenia é considerado uma luta diária contra o sofrimento que é agravado em períodos de crise e perda das habilidades ${ }^{(1)}$.

Os principais sintomas clínicos da doença são caracterizados em dois tipos, sendo um denominado de positivo e outro negativo. Os sintomas positivos correspondem a delírios e alucinações, e os sintomas negativos ao embotamento afetivo, comprometimento cognitivo e déficit de memória, sendo ambos os sintomas os responsáveis pela imagem do louco na sociedade, como sendo aquela pessoa agressiva, introspectiva e que deve ser isolada socialmente ${ }^{(2,3)}$.

Existe um intervalo de tempo entre o surgimento dos sintomas e a procura pelo tratamento, o que pode influenciar em um mau prognóstico, pois assim os sintomas tornam-se mais intensos, necessitando de maior tempo de tratamento psicofarmacológico e com doses mais elevadas da medicação. A intervenção adequada envolve o tratamento farmacológico, psicossocial e a inclusão familiar ${ }^{(4)}$.

O transtorno esquizofrênico é igualmente prevalente entre homens e mulheres; entretanto, no homem, o problema tem início mais precoce, entre 10 e 25 anos; em geral a primeira internação acontece antes dos 25 anos. Já entre mulheres a idade de maior pico do adoecimento é entre 25 e 30 anos, tornando o prognóstico mais favorável para a mulher em relação ao 
homem, devido ao início mais tardio(4). A esquizofrenia pode se manifestar de forma insidiosa ou aguda, contudo evidencia-se uma fase prodrômica caracterizada por isolamento social e vivências com ausência de respostas emocionais ${ }^{(5)}$.

Sobre os episódios de crises vivenciados pela pessoa com esquizofrenia, estudo revelou que apenas $5 \%$ dos pacientes apresentam um único surto durante toda a vida; a maioria apresenta vários surtos, grande parte nos primeiros anos da doença. Isso mostra que a evolução da doença demanda o envolvimento de familiares no cuidado ou acompanhamento da pessoa com o transtorno e isso poderá desenvolver uma sobrecarga física e emocional de familiares dedicados a exercer o cuidado, considerando que a esquizofrenia é um tipo de transtorno com elevado potencial para a cronicidade ${ }^{(1)}$.

Quando os familiares descobrem a esquizofrenia em seu lar, estes vivenciam uma nova fase, na qual emergem sentimentos variados. O impacto gerado na família em razão do adoecimento causa situações de estresse, cansaço e desesperança; pois, muitas vezes, não é entendido o que está realmente acontecendo com o seu familiar. Conviver com um ente portador de esquizofrenia pode ser uma experiência angustiante, na medida em que emergem sentimentos de incerteza quanto ao presente e ao futuro do seu familiar, que envolvem as suas próprias perspectivas de vida ${ }^{(6)}$.

Estudo realizado com familiares de pessoas com esquizofrenia apontou que o cuidador sofre sobrecargas físicas e emocionais, ocasionadas pelos desgastes provocados pelo comportamento de seus doentes, por terem que dedicar tempo e assumirem a tarefa de cuidar cotidianamente, uma vez que o transtorno esquizofrênico, além das limitações funcionais desencadeadas na vida da pessoa doente, ainda desperta muito preconceito na sociedade e isso demanda mais proteção e cuidados à pessoa que sofre com a esquizofrenia ${ }^{(1)}$.

O cuidado à pessoa com esquizofrenia exige dos familiares uma alteração nas suas atividades sociais cotidianas e nas suas tarefas, que passam a ser exercidas por outras pessoas, pois ele precisa de tempo para se dedicar ao cuidado do doente, colocando os familiares em condição de prejuízo pessoal e de sofrimento acarretado pela carga de estresse gerada do cuidado diário, pois a família representa peça fundamental no tratamento e recuperação da pessoa com esquizofrenia ${ }^{(7)}$.

Diante do exposto, considerando que a família representa importante recurso no cuidado e reabilitação da pessoa com esquizofrenia, entendemos que conhecer as vivências relatadas por familiares da pessoa com esquizofrenia poderá apoiar no desenvolvimento de estratégias de cuidado à pessoa com transtorno mental; bem como, desenvolver medidas para promoção da saúde de familiares e cuidadores.

Para isso, compartilhamos o entendimento de vivências a partir de um estudo desenvolvido por Barretta ${ }^{(8)}$ apoiado nas concepções de Freud e Husserl. O autor diz que o termo vivência é utilizado de modo a englobar ambos os sentidos de vivenciar e de vivido. Trata-se ao mesmo tempo de uma experiência imediatamente vivida, isto é, não presumida, nem meramente ouvida, mas direta e pessoalmente realizada; ao mesmo tempo em que se trata de uma experiência duradoura, significativa, ainda que em geral no sentido patológico. Em suma, o mesmo autor destaca que o termo "vivência" é empregado para referir-se a uma experiência direta e pessoal de alguma coisa, mas que é também determinante, significativa, na vida de uma pessoa.

Neste contexto, este estudo tem como objetivos descrever as vivências de familiares da pessoa com esquizofrenia.

\section{Materiais e Métodos}

A pesquisa social pode ser entendida como os vários tipos de investigação que tratam do ser humano em sociedade, de suas relações e instituições, de sua história e de sua produção simbólica. Este tipo de método procura "desvelar" processos sociais que ainda são pouco conhecidos e que pertencem a grupos particulares, sendo seu objetivo e indicação final, proporcionar a construção e/ou revisão de novas abordagens, conceitos e categorias referentes ao fenômeno estudado(9).

Nesta perspectiva, esta pesquisa adotou os preceitos de uma pesquisa de caráter qualitativodescritivo, visando buscar analisar a vivência de familiares da pessoa com esquizofrenia. Para isso, a pesquisa teve como cenário um Centro de Atenção Psicossocial (CAPS), localizado no município de Teresina $(\mathrm{PI})$.

Os participantes do estudo foram familiares de pessoas com esquizofrenia, acompanhadas no referido CAPS selecionado para o estudo. O número de participantes foi de 12 (doze) familiares, contudo por se tratar de um estudo de natureza qualitativo, o número de participantes envolvidos no estudo foi definido a partir do critério de saturação das falas aplicado em pesquisa desta natureza.

Os critérios de inclusão definidos para a participação no estudo foram: familiar da pessoa com esquizofrenia, maiores de 18 anos, de ambos os sexos, independente 
do grau de parentesco, mas que convive no mesmo domicílio com a pessoa com esquizofrenia. Quanto aos critérios de exclusão na pesquisa, estes foram representados por: familiar da pessoa com esquizofrenia, mas que não convive com a pessoa doente; além de familiar que convive no mesmo domicílio, mas que não tenha idade superior a 18 anos de idade.

A coleta de dados foi realizada no mês de novembro de 2015. Para isso foi aplicado um roteiro de entrevista semiestruturado, contendo perguntas fechadas para caracterizar o perfil dos participantes do estudo e questões abertas relacionadas às vivências de familiares da pessoa com esquizofrenia.

O encontro entre entrevistador e entrevistado deuse no próprio Centro de Atenção Psicossocial onde este frequenta, em ambiente que assegurou o respeito, conforto, segurança e privacidade do participante. Além disso, foram aplicados todos os procedimentos recomendados pela Resolução $n^{\circ} 466 / 12$ para garantir os esclarecimentos detalhados sobre a pesquisa ao participante, por meio da leitura e assinatura de Termo de Consentimento Livre e Esclarecido (TCLE) (10). Ainda, para o cumprimento da citada Resolução, os participantes foram identificados por nome de flores para garantir o anonimato.

Contudo, para realização do estudo, o projeto de pesquisa foi encaminhado à Fundação Municipal de Saúde (FMS) de Teresina, instituição coparticipante na pesquisa e, em seguida, encaminhado ao Comitê de Ética e Pesquisa (CEP) do Centro Universitário UNINOVAFAPI, sendo aprovado sob o CAAE 49462715.3.0000.5210.

A análise dos dados seguiu os pressupostos da técnica de análise de conteúdo à luz do referencial teórico de Bardin(11), que permitiu a formação de categorias temáticas.

\section{Resultados e Discussão}

Responderam ao instrumento de entrevista, 12 pessoas com idade entre 22 a 76 anos. Entre estas, predominou a faixa etária acima de 60 anos (com 4 participantes) e pessoas do gênero feminino, totalizando 11 participantes. Além disso, o grau de parentesco mais encontrado entre os entrevistados foram pessoas do primeiro grau de parentesco (mãe). Ainda sobre os participantes, a maioria era casado (5 participantes), com ensino fundamental, desempregado e de religião católica (com 8 participante em cada variável).

A pesquisa visou à obtenção de informações que permitiram descrever as vivências de familiares da pessoa com esquizofrenia atendendo aos objetivos deste estudo. Os resultados foram agrupados nas seguintes categorias que serão discutidas a seguir:

\section{Medo vivenciado pelo familiar da pessoa com esquizofrenia e o difícil convívio familiar}

Entre as alterações psíquicas presentes na esquizofrenia destacam-se as alucinações que produzem significativas mudanças de comportamento, levando a manifestações de comportamento instável e, muitas vezes, agressivo. Em casos mais graves, a pessoa com esquizofrenia revela extrema desorganização do pensamento e isso torna a convivência familiar, ou com o cuidador, profundamente prejudicada, muitas vezes marcada por medo e insegurança diante da agressividade. Tais vivências foram referidas pelos participantes deste estudo.

Tem dia que ele tá bom, tem dia que não tá. Tem dia que ele xinga e eu todo tempo aguentando, tem dia que eu estou sem paciência, dá vontade até de sair porque a pessoa que luta com essas pessoas acaba, também, ,ficando com problema. [...] No começo eu chorava tanto porque ele ficava falando com gente que já morreu, e eu tenho medo dele fazer alguma coisa comigo quando eu estiver dormindo. (Rosa)

Outra participante acrescenta que [...] é muito difícil, ele é uma pessoa assim, porque você sabe que essas pessoas sempre escolhem uma pessoa na família, a nossa família são de doze pessoas, mas só quem corre atrás das coisas sou eu e minha irmã que luta com ele. Ele já fez tentativa de estupro, ele é muito agressivo naquele momento que ele tá em crise você tem que ceder à vontade dele se não ele até Ihe mata, então é muito difícil! (Tulipa)

Conforme relatado nos depoimentos acima, o convívio com a pessoa com esquizofrenia é uma tarefa exaustiva, em virtude das alterações comportamentais que desorganizam o indivíduo, produzindo sintomas que incluem agressividade e pensamento incompatível com a realidade ${ }^{(12)}$.

A prolongada convivência do familiar com a pessoa que sofre de esquizofrenia, muitas vezes assumindo o cuidado em tempo integral e exposto, cotidianamente, a jornada excessiva de tempo dedicado ao cuidado de seu ente doente, produz no familiar - cuidador significativos problemas de saúde, tanto de ordem física como psíquica. São comuns problemas cardíacos, estresse, tensão, medo, nervosismo, isolamento, desânimo, ansiedade e sintomas psicossomáticos, além do possível desenvolvimento de um transtorno mental.

Minha convivência é muito sufocada, porque ele é muito agressivo. Ele até me bate! Um tempo desse ele estava internado, ai ele pegou uma sacola de roupa [...] e saiu. Ainda estava assim escuro, cinco horas da manhã, quando eu fui 
atrás dele para procurar pela sacola, a resposta que ele me deu foi uma tapona, me socou de murro, fiquei toda manchada de soco que ele me deu. Então é muito difícil. (Gardênia)

Isto aponta para a necessidade de dedicar aos familiares e cuidadores mais apoio, informações e esclarecimentos sobre os transtornos mentais e as formas de lidar e conviver com a pessoa que sofre com a esquizofrenia( ${ }^{(8)}$.

Estudo realizado com cuidadores de pessoas com esquizofrenia mostrou que o cuidador sofre sobrecargas físicas e emocionais, ocasionadas pelos desgastes provocados pelo comportamento de seus doentes, tornando extremamente difícil o convívio familiar ${ }^{(13)}$.

Por isso, investir nos tratamentos medicamentoso e psicossocial representam importantes medidas de cuidado à pessoa com transtorno esquizofrênico e constituem em elementos facilitadores para a convivência familiar ${ }^{(12)}$.

Outra questão revelada pelos depoimentos levantados neste estudo está relacionada à necessidade de maior atenção por parte dos profissionais em proporcionar acolhimento e esclarecimentos aos familiares e cuidadores sobre o transtorno mental e manejo diante das situações de crise. Sobre isso, o depoimento a seguir destaca que:

É complicado porque você tem que entender algumas coisas né, porque muda muito, às vezes. Períodos quando não tem medicação fica difícil, tem que ter medicação constante por isso ele está aqui, no mais ele é alegre, muito brincalhão, tem vários amigos e a doença não impediu tanto isso, e ele só é assim controlado por causa da medicação. (Jasmim)

Desta forma, o depoimento de Jasmim aponta para a necessidade de estabelecer condutas voltadas não somente para acolher o sofrimento, mas também para garantir aos familiares e cuidadores orientações que possam contribuir para a adesão da família ao serviço e, assim, além de atender à pessoa com transtorno esquizofrênico, ofertar apoio e cuidados aos familiares ${ }^{(9)}$.

É preciso considerar que a convivência da família com a pessoa com transtorno mental nem sempre é harmoniosa; comumente é permeada por tensões e conflitos, uma vez que é nesse espaço que as emoções são mais facilmente expressadas ${ }^{(12-13)}$. Somado a isso, a família ainda vivencia excessiva preocupação com a segurança e a proteção da pessoa com transtorno esquizofrênico, pois os episódios de autoagressividade podem se manifestar com comportamento suicida.

Ele já tentou se matar com um saco de lixo, ele enrolou no pescoço estava sem folego. Quando ele tá sem tomar o remédio ele fica agressivo, agora ele tomando, não; fica normalzinho. Quem vê diz que nem toma remédio. É muito difícil minha convivência com ele, mas é meu filho, tenho que suportar, eu amo ele de todo meu coração. (Cravo)
Ela é agressiva [...] ela, ela é teimosa; tacou a mão aí no poste. Ela é agressiva até com a mãe dela. A mãe dela não gosta de andar com ela, porque não se dá bem com ela. Essa mulher ai é um caso sério, tem dia que ela me atende, às vezes ela me atende, dentro de casa ela faz as coisinhas dela direitinho, mas é agressiva demais. (Girassol)

As manifestações de agressividade, presentes no relato da maioria dos participantes, constituem um dos maiores obstáculos para a boa interação entre a pessoa doente e o familiar. Geralmente, os familiares não tem manejo adequado para o controle desse quadro. Além disso, a dificuldade em garantir a adesão ao tratamento medicamentoso e a inserção em dispositivos de reabilitação contribuem para agravar ainda mais o estado do paciente que passa a desencadear crises mais frequentes.

\section{Sobrecarga psicológica vivenciada pelo cuidador e a adaptação da família ao problema}

Quando os familiares descobrem a esquizofrenia em seu lar, estes vivenciam uma nova fase na qual emergem sentimentos variados. O impacto gerado na família em razão do adoecimento causa situações de estresse, cansaço e desesperança; pois, muitas vezes, não é entendido o que está realmente acontecendo com o seu familiar doente. Conviver com um ente portador de esquizofrenia pode ser uma experiência angustiante, na medida em que emergem sentimentos de incerteza quanto ao presente e ao futuro do mesmo, que envolvem as suas próprias perspectivas de vida $^{(6)}$.

Neste sentido, participantes deste estudo falam que: é difícil porque ver o jeito dela, a situação dela, sem a pessoa poder fazer nada e ela só ficar dopada vinte e quatro hora, é difícil! Ela não é agressiva, é todo tempo na dela, quietinha, todo tempo dopada e é difícil porque eu não posso fazer nada pra ajudar. (Orquídea)

Nós temos vinte anos de casado, no começo era tão bom! Mas, depois, ela começou a ter essas crises. No começo foi horrível! Mas, depois, fui me adaptando porque sou responsável por ela; eu já tenho costume com isso; eu tenho mais paciência, já meu filho, às vezes ele não entende, quando ela tá nos dia de crise falando coisa com coisa, ele não entende, acha que é coisa dela mesma. (Lírio)

A família é considerada indispensável para a efetividade da assistência psiquiátrica e entendida como um grupo com grande potencial de acolhimento e ressocialização de seus integrantes ${ }^{(9)}$. Contudo, para isso, é necessário que profissionais de saúde possam garantir suporte aos cuidadores a fim de prepará-los para o manejo inclusive nas situações de crise. 
Minha convivência com ele é boa, porque ele não é agressivo, ele é agressivo assim, nas coisas de casa, às vezes ele fica. Joga as coisas no mato, vira geladeira, vira fogão, mas também não é todo dia. Comigo, graças a deus, ele não é agressivo. Minha convivência é boa. Agora, o negócio é que ele conversa demais só. Ele diz que os homens estão atrás dele; joga a comida na parede. (Violeta)

É boa, no começo era ruim, porque tá com nove meses que meu irmão faleceu, ela piorou muito, ai o médico começou a passar outra medicação pra ela, e ela melhorou muito. Ela não traz nenhum problema, não. Ela só é agressiva na hora de falar. (Margarida)

Apesar do desgaste físico e emocional vivenciado pelos familiares e cuidadores, verifica-se que, em muitos casos, há a busca e tentativa em manter um estado de equilíbrio diante do problema. É como se o familiar dedicado ao cuidado da pessoa com esquizofrenia encontrasse recursos pessoais de proteção e ajuda para o enfrentamento da condição de sofrimento que vivencia, revelando uma aceitação da pessoa doente e habilidades na tarefa de cuidar, conforme é relatado a seguir:

A gente vê muita família que sofre porque o paciente é muito agressivo, ele não, ele não ofende ninguém, ele não é agressivo com ninguém, mas quando ele tá sentindo uma dor, ele puxa os cabelo da cabeça. Nesse período, do segundo semestre, ele fica bem mais agitado; e é ruim pra gente e pra ele. Quando tá chovendo e não tá tanto calor, ele é bem mais calmo. Tem a fase que ele tá super em paz, mas tem a fase que ele tá agressivo, rasga tudo. (Hortência)

Não é ruim minha convivência com ele; é só eu de mulher e três homens em casa, e quando ele tá sem tomar a medicação ele fica muito agressivo mas, agora ele tá tomando injeção aí tá bom, ele só me agride com palavrão. (Camomila)

Com o intuito de compartilhar o cuidado da pessoa com transtorno mental entre os profissionais de saúde mental e os próprios familiares, a atual política nacional de saúde mental estimula o desenvolvimento de atividade que promovam o acolhimento e orientações da família e da pessoa com transtorno mental a fim de prepará-los para o desenvolvimento do cuidado. Desse modo, os Centros de Atenção Psicossocial (CAPS) instituíram no seu cardápio de ofertas grupos terapêuticos com familiares. Nesta ação, os familiares além de serem instruídos sobre o manejo e cuidados com a pessoa doente, recebem cuidados para diminuir os fatores estressantes e prevenir adoecimentos.

\section{Considerações finais}

O presente estudo possibilitou conhecer as vivências de familiares da pessoa com transtorno mental e o impacto gerado na vida destes que cuidam de um membro da sua família com transtorno mental. Assim, os participantes deste estudo revelaram que vivenciam situações de medo, agressividade, cansaço, preocupação e estresse que resultam em condições de desgaste físico e emocional de familiares/cuidadores. Além disso, o estudo revelou a carga de prejuízos sociais e psíquicos que dificultam o convívio com a pessoa com transtorno esquizofrênico.

No entanto, vale destacar que embora diante das dificuldades reveladas pelos participantes do estudo, estes buscam adaptação e aceitação de seu ente familiar vivendo com a esquizofrenia.

Diante desses resultados, podemos apontar para a necessidade de dedicar maior atenção e orientação aos familiares cuidadores da pessoa com transtorno mental, neste estudo destacando a pessoa com esquizofrenia, com o intuito de preparar familiares para a missão do cuidado e, deste modo, ampliar e fortalecer a rede de cuidados à pessoa com transtorno mental.

Concluímos que a família se insere como suporte de apoio, acolhimento e amor àquele que mentalmente adoece e precisa compreender que seu papel pode ser imprescindível para a evolução do tratamento daquele com diagnóstico de transtorno mental; bem como, na promoção da saúde e prevenção de adoecimento de outros integrantes do núcleo familiar.

Espera-se que este estudo ajude os estudantes e os profissionais da saúde a conhecerem, a partir do relato dos familiares da pessoa com esquizofrenia, o real sofrimento ocasionado por esta difícil convivência e que, a partir deste conhecimento, reflitam sobre suas práticas cotidianas, uma vez que, independente da área em que o profissional da saúde escolha atuar, sempre haverá oportunidade de acolher a pessoa com transtorno mental com dignidade e respeito à sua cidadania.

\section{Referências}

1. Giacon B, Galera S. Ajustamento familiar após o surgimento da esquizofrenia. Rev. bras. enferm. 2013; 66(3):321-26.

2. Cordeiro FR, Terra MG, Piezak DR, Ely GZ, Freitas FF, Silva AA. Cuidados de enfermagem à pessoa com esquizofrenia: revisão integrativa. Rev Enferm UFSM. 2012; 2(1):174-181.

3. Queiroz AIG, Oliveira GAL, Freitas RM. Associação de antipsicóticos e vitaminas (ácido ascórbico, alfa-tocoferol e complexo b) e seu papel na memória de portadores de esquizofrenia. Revista Eletrônica de Farmácia. 2012; 9(2): $61-75$. 
4. Sakaguchi DS. Transtornos Psicóticos: Transtorno Esquizofrênico. In: Marcolan JF, Castro RCBR, org. Enfermagem em saúde mental e psiquiátrica: desafios e possibilidades do novo contexto do cuidar. 1. ed. Rio de Janeiro: Elsevier; 2013. cap. 7. p. $69-80$.

5. Stefanelli MC, Fukuda IMK, Arantes EC, Forcella HT et al., Assistência de enfermagem à pessoa com manifestações de comportamento decorrentes de esquizofrenia, transtornos esquizotípicos e transtornos delirantes. In: Stefanelli MC, Fukuda IMK, Arantes EC, org. Enfermagem psiquiátrica e suas dimensões assistenciais. Barueri, SP: Manole, 2008. cap. 23. p. $415-438$.

6. Sales CA, Schuhli PAP, Santos EM, Waidman MAP, Marcon SS. Vivências dos familiares ao cuidar de um ente esquizofrênico: um enfoque fenomenológico. Rev. Eletr. Enf. [Internet]. 2010;12(3):456-63.

7. Schülhi PAP, Wadman MAP, Sales CA. O cotidiano familiar da pessoa com esquizofrenia: cuidando no domicílio. Rev. Eletr. Enf. [Internet]. 2012 jan/mar; 14(1):16-24.

8. Barretta JPF. O conceito de vivência em Freud e Husserl. Psicologia USP, São Paulo, janeiro/março, 2010, 21(1), 47-78.

9. Minayo MCS. O desafio do conhecimento: Pesquisa Qualitativa em Saúde. (12ª edição). São Paulo: HucitecAbrasco. 2010.

10. Conselho Nacional de Saúde (Brasil). Resolução $n^{\circ}$ 466, de 12 de dezembro de 2012. Brasília, 2012.

11. Bardin L. Análise de Conteúdo. Lisboa: $4^{a}$ Edição, 2009. 12. Brischk CCB, Loro MM, Rosanelli CLP, Cosentino SF, Gentile CS, Kolankiewicz ACB. Convivendo com a pessoa com esquizofrenia: perspectiva de familiares. Cienc Cuid Saude 2012 Out/Dez; 11(4):657-664.

13. Almeida MMA, Schal VT, Martins AM, Modena CM et al. A sobrecarga de cuidadores de pacientes com esquizofrenia. Rev Psiquiatr. Rio Gd Sul. 2010;32(3):73-79. 